\title{
Iğdır Ekolojik Koşullarında Yetişen Doğal Yonca (Medicago Sativa L.) Genotiplerinin Kalite Özelliklerinin Belirlenmesi
}

\author{
Barıș Eren $^{1 *}$, Bilal Keskin ${ }^{2}$ \\ ${ }^{1}$ Iğdır Üniversitesi, Ziraat Fakültesi, Tarımsal Biyoteknoloji Bölümü, Iğdır (ORCID: 0000-0002-3852-6476), bariseren86@ gmail.com \\ 2 Iğdır Üniversitesi, Ziraat Fakültesi, Tarla Bitkileri Bölümü, Iğdır (ORCID: 0000-0001-6826-9768), bilalkeskin66@yahoo.com
}

(İlk Geliş Tarihi Aralık 2020 ve Kabul Tarihi Ocak 2021)

(DOI: $10.31590 /$ ejosat.851712)

ATIF/REFERENCE: Eren, B., Keskin, B. (2021). Iğdır Ekolojik Koşullarında Yetişen Doğal Yonca (Medicago Sativa L.) Genotiplerinin Kalite Özelliklerinin Belirlenmesi. Avrupa Bilim ve Teknoloji Dergisi, (22), 19-26.

\section{Öz}

Bu araştırma; 2018 yılında Iğdır ekolojik koşullarında doğal olarak yetişen 48 yonca genotip ve 2 sertifikalı Adi yonca (Medicago sativa L.) materyali kullanılarak yürütülmüştür. Deneme Iğdır Üniversitesi Tarımsal Uygulama ve Araştırma Merkezine ait deneme alanında yürütülmüştür. Iğdır popülasyonunu temsil edecek şekilde 16 lokasyon ve her bir lokasyonda 3 örnek olmak üzere 48 yonca genotipi toplanmıştır. Toplanan yonca genotipleri klonlama işlemiyle çoğaltıldıktan sonra, tesadüf blokları deneme desenine göre 3 tekerrürlü olarak deneme tarlasına şaşırtılmıştır. Hasat işlemleri \%10 çiçeklenme döneminde yapılarak bitkiler kurutma işleminden sonra öğütülerek analiz çalışmalarına hazır hale getirilmiştir. Araştırmada, kalite özelliklerine ait ham protein (HP), nötr çözücülerde çözünemeyen lif (NDF), asit çözücülerde çözünemeyen lif (ADF), asit çözücülerde çözünemeyen lignin (ADL), kuru madde sindirilebilirliği (KMS), sindirilebilir enerji (SE), metabolik enerji (ME), kuru madde tüketimi (KMT) ve nisbi yem değeri (NYD) özellikleri incelenmiştir. Araştırma sonuçlarına göre; genotipler arasında besin kalite özellikleri sonuçlarına göre en yüksek HP, KMS, SE, ME, KMT ve NYD değerleri Sunter yonca çeşidinde elde edilmiştir. Bununla birlikte NDF, ADF ve ADL özelliklerine ait en yüksek değerler 33 numaralı yonca genotipinden elde edilmiştir. Islah çalışmalarında kalite özelliklerinin geliştirilmesi hayvan beslemesi açısından oldukça önem arz etmektedir. Elde edilen verilere göre kalite özellikleri açısından 4, 18, 20, 25, 39 ve 45 numaralı yonca genotiplerinde iyileştirmeye yönelik ıslah çalışmaları yapılabilir.

\section{Determination of Quality Characteristics of Natural Alfalfa (Medicago Sativa L.) Genotypes Grown in Iğdır Ecological Conditions}

\begin{abstract}
This research; It was conducted in 2018 using 48 alfalfa genotypes and 2 certified Common clover (Medicago sativa L.) material, which grows naturally in Iğdır ecological conditions. The experiment was conducted in the experimental area of Iğdır University Agricultural Application and Research Center. It was planned to collect a total of 48 clover genotypes in 16 locations and 3 samples at each location to represent the Iğdır population. After the collected clover genotypes were replicated by cloning process, the random blocks were confounded in the trial field in 3 replications according to the experimental design. Harvesting was done with $10 \%$ flowering and the plants were prepared for analysis by grinding them after drying. In the research, crude protein (CP), neutral detergent fiber (NDF), acid detergent fiber (ADF), acid detergent lignin (ADL), dry matter digestibility (DMD), digestible energy (DE), metabolizable energy (ME), dry matter intake (DMI) and relative feed value (RFV) were examined. According to the research
\end{abstract}

\footnotetext{
*Sorumlu Yazar: bariseren86@gmail.com
} 
results; Among the genotypes, the highest CP, DMD, DE, ME, DMI and RFV values were obtained from the Sunter alfalfa variety according to the nutritional quality characteristics. However, the highest values of NDF, ADF and ADL properties were obtained from clover number 33 genotype. Improving quality characteristics in breeding studies is very important in terms of animal nutrition. According to the data obtained, breeding studies can be carried out to improve clover genotypes numbered 4, 18, 20, 25, 39 and 45 in terms of quality characteristics.

Keywords: Alfalfa, Genotype, CP, ADF, NDF.

\section{Giriş}

Canlı varlıkların besinleri ya bitkilerden ya da bitkiler ile beslenen hayvanlardan elde edilmektedir. Bu nedenle tarımsal üretimin en önemli amacı bitkilerden en yüksek verimi elde etmek için uygun koşulların sağlanmasıdır. Tarımsal üretimde özellikle hayvan beslemede en önemli faaliyet şüphesiz yem bitkilerinin ekimidir. Yem bitkileri tarımının, Türkiye ve Dünyadaki önemi giderek artmaktadır. Yem bitkileri ve çayırmera alanlarımızın daha verimli ve kaliteli olması temel hedeflerimizden biri olmalıdır (Keskin ve ark., 2020). Artan dünya nüfusuyla birlikte büyüyen beslenme problemi, beklenen en büyük sorunların başında gelmektedir. Dünya nüfusu hızla artmakta ve azalan doğal kaynakları dengelemek için verim ve kaliteyi arttırmak için yeni zirai bitki çeşitleri geliştirmek gerekir (Demirel ve ark., 2020). Artan dünya nüfusuna karşın tarım arazilerinin sınırlı olması bilim insanlarını, birim alanda daha fazla verim alacak yeni çeşitlerin geliştirilmesi için ıslah yöntemlerine yönlendirmiştir. Bunun yapılabilmesi için bitki ıslahında en önemli kaynağın hiç şüphesiz genetik kaynaklar olduğu kabul edilmektedir. Bu nedenle bir bitki ıslahçısının en büyük yardımcısının bitkisel gen kaynakları olduğunu söyleyebiliriz (Şehirali ve Özgen, 1987). Geçmişten günümüze yapılan klasik ıslah çalışmaları sayesinde önemli birçok tarımsal üründe hem kalitatif hem de kantitatif olarak ciddi boyutlarda kazanımlar olmuştur.

Baklagiller hayvan beslemede ve insanların günlük protein ihtiyacını karşılamada buğdaygillerden sonra gelen en önemli familyadır (Şakiroğlu ve ark., 2011; Eren ve ark. 2018). Dünya nüfusundaki artış ve beslenme gereksimi baklagillerin önemini daha da arttırmıştır (Kaçar ve ark., 2005). Baklagil familyasına ait birçok bitki türü, karbonhidrat içeriği, yeterli yağ oranı ve özellikle yüksek protein miktarlarından dolayı hayvan besini olarak kullanılan önemli bir yem kaynağıdır (Ferber, 1999; Phillips, 2006; Verdier et al., 2008). İnsanlar, günlük protein ihtiyacının üçte birini bitkisel proteinlerden yani baklagil bitkilerinden sağlamaktadır. Bunun yanında azot için ihtiyaç duyulan besinin yaklaşık olarak \%30 unu baklagiller sağlamaktadır (Açıkgöz, 2001; Suzan, 2008). Bu özelliklerinden dolayı baklagiller familyası gelişmiş ülkelerde tarımsal faaliyetlerde, insan ve hayvan besleme açısından önemli bir yer edinmektedir (Graham and Vance, 2003).

Yonca bitkisi Dünyada en çok yetiştiriciliği yapılan çok yıllık bir yem bitkisidir. Yonca bitkisi hayvan beslemede yaş ve kuru ot olarak tüketilebildiği gibi silajı yapılarak da kullanılabilmektedir. Dünyanın birçok yerinde ayrıca ülkemizin hemen her bölgesinde üretimi rahatlıkla yapılabilmektedir. Birim alanda içerdiği yüksek protein miktarından dolayı besleme değeri yüksektir. Yonca bitkisi diğer yem bitkilerinden daha yüksek yem değerine sahip olduğu için yem bitkilerinin kraliçesi olarak da adlandırılmaktadır (Yeşil ve Şengül, 2009). Yonca bitkisi sahip olduğu kaliteli kaba ot verimiyle hayvan besleme açısından yeşil ya da kuru ot olarak her türlü hayvan için besleme değeri yüksek ve lezzetlidir (Açıkgöz, 2001). Yonca bitkisi her türlü sslah çalışmalarında verim ve kalite yönünden ciddi sonuçlar alınabilecek karaktere sahip bir bitkidir. Yonca bitkisinin üstün özelliklerinden dolayı, değişken ortam şartlarına adaptasyonu, tohum gelişimi, her türlü zararlılaya karşı direnç kazandırmak, kuraklık ve hastalık benzeri stres faktörlerine dayanıklı ve en önemlisi verim ve kalite yönünden üstün genotiplerin geliştirilmesi hedeflenmelidir (Ferber, 1999; Phillips, 2006). Yonca genotiplerinde yapılan islah çalışmaları geçmiş tarihlerden bu yana olumlu sonuçlar vermiştir (Eren, 2014). Fakat son yıllarda yapılan çalışmalar incelendiğinde verim artışı için yapılan ıslah çalışmalarında diğer bitkilerle kıyaslandığında o kadar da etkili stratejiler geliştirildiği söylenemez (Şakiroğlu ve ark., 2015).

92.200 hektarlık bir alana ve eşsiz bir iklime sahip Iğdır ili, 686.278 dekarlık işlenen bir tarım arazisine sahiptir ve Türkiye'nin toplam işlenmiş tarım arazisinin yaklaşık \% 0,28'ini kapsamaktadır. Ayrıca, yonca bitkisi Iğdır ilinde yetiştiriciliği yapılan önemli yem bitkileri arasında olduğu bildirilmiştir (Eren ve ark., 2017). Hayvan beslemede günlük besin ihtiyacının karşılanmasında bitki kalite özellikleri açısından en uygun çeşitlerin ortaya çıkarılması için yem kalite özelliklerinin bilinmesi oldukça önemlidir. Ülkemiz yonca bitkisinin önemli bir gen merkezi olması sebebiyle Iğdır ili yonca popülasyonunda farklı gen kombinasyonuna sahip toplam 48 yonca genotipinde yem kalite açısından üstün yonca genotiplerinin elde edilmesi amaçlanmıştır.

\section{Materyal ve Metot}

$\mathrm{Bu}$ çalışma, 2018 yıllında Iğdır Üniversitesi Tarımsal Uygulama ve Araştırma merkezine ait deneme tarlasında tesadüf bloklar deneme desenine göre 3 tekerrürlü olarak kurulmuştur. Çalışma materyalini, Iğdır İli doğal ekolojik koşullarda yetişen adi yonca (Medicago sativa L.) genotipleri ile Sunter ve Kayseri yonca çeşitleri oluşturmuştur. Iğdır ekolojik şartlarındaki yonca genotiplerinin popülasyonunu temsil edecek şekilde 16 lokasyon ve her lokasyonda 3 bitki olacak şekilde belirlenmiştir (Tablo 1). Yonca genotipleri çiçeklenme başlangıcıyla toplanmış ve klonlama yöntemiyle her parselde $50 \times 50 \mathrm{~cm}$ olacak şekilde toplam 10 yonca klonu parsellere şaşırtılmıştır. Klonlama basit çelik yöntemiyle, genç sürgünlerden 2-3 göz içerecek şekilde uçtan itibaren ikinci ya da üçüncü boğumdan ve yaprak boğumunun yaklaşık $1 \mathrm{~cm}$ yukarısından kesilerek alınmıştır (Elçi ve Sevimay, 1990)

Deneme alanına ait uzun yıllar iklim verileri incelendiğinde, nispi nemin $\% 50,9$, ortalama sıcaklık $18,3{ }^{\circ} \mathrm{C}$ ve toplam yağ 1 ş miktarının 204,0 mm olduğu görülmektedir (MGM, 2018). Denemeye yerine ait 2018 Mart-Ekim aylarına ait ortalama nisbi nem $\% 50,9$, ortalama sıcaklık ise $20,2^{\circ} \mathrm{C}$, toplam yağış miktarı $180,9 \mathrm{~mm}$ olarak belirlenmiş ve bu veriler doğrultusunda denemenin yürütüldüğü yetişme sezonu, uzun yıllar ortalamasına göre sıcak ancak yağış miktarı daha az bir yıl olduğu belirlenmiştir (Tablo 2). 


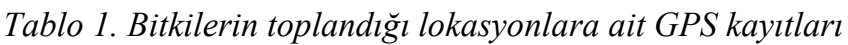

\begin{tabular}{ccc}
\hline Lokasyonlar & Kordinatlar & Rakım (m) \\
\hline Gödekli Köyü & $39^{\circ} 49^{\prime} 11.7^{\prime \prime} \mathrm{N} 44^{\circ} 35^{\prime} 37.5^{\prime \prime} \mathrm{E}$ & 808 \\
\hline Aralık İlçesi & $39^{\circ} 53^{\prime} 22^{\prime \prime} \mathrm{K} 44^{\circ} 31^{\prime} 09^{\prime \prime} \mathrm{D}$ & 821 \\
\hline Hasanhan Köyü & $39^{\circ} 57^{\prime} 22.2^{\prime \prime} \mathrm{N} 44^{\circ} 20^{\prime} 34.4^{\prime \prime} \mathrm{E}$ & 826 \\
\hline Saraçlı Köyü & $39^{\circ} 54^{\prime} 40.9^{\prime \prime} \mathrm{N} 44^{\circ} 28^{\prime} 02.5^{\prime \prime} \mathrm{E}$ & 817 \\
\hline Taşburun Beldesi & $39^{\circ} 58^{\prime} 51^{\prime \prime} \mathrm{K} 44^{\circ} 14^{\prime} 48^{\prime \prime} \mathrm{D}$ & 825 \\
\hline Karakoyunlu İlçesi & $39^{\circ} 58^{\prime} 21^{\prime \prime} \mathrm{K} 44^{\circ} 10^{\prime} 22^{\prime \prime} \mathrm{D}$ & 848 \\
\hline Tacirli Köyü & $39^{\circ} 59^{\prime} 14^{\prime \prime} \mathrm{K} 44^{\circ} 06^{\prime} 39^{\prime \prime} \mathrm{d}$ & 846 \\
\hline Suveren Köyü & $39^{\circ} 48^{\prime} 32.1^{\prime \prime} \mathrm{N} 44^{\circ} 04^{\prime} 26.9^{\prime \prime} \mathrm{E}$ & 1200 \\
\hline Iğdır Merkez & $39^{\circ} 55^{\prime} \mathrm{K} 44^{\circ} 02^{\prime} \mathrm{D}$ & 850 \\
\hline Halfeli Beldesi & 860 \\
\hline Hoşhaber Beldesi & 870 \\
\hline Küllük Köyü & $39^{\circ} 53^{\prime} 17^{\prime \prime} \mathrm{K} 43^{\circ} 59^{\prime} 19^{\prime \prime} \mathrm{D}$ & 880 \\
\hline Bayraktutan Köyü & $39^{\circ} 55^{\prime} \mathrm{K} 43^{\circ} 57^{\prime} \mathrm{D}$ & 888 \\
\hline Köprübaş1 Köyü & $39^{\circ} 59^{\prime} 00^{\prime \prime} \mathrm{K} 43^{\circ} 54^{\prime} 0$ "D & 1000 \\
\hline Hamurkesen Köyü & $40^{\circ} 00^{\prime} 00^{\prime \prime} \mathrm{K} 43^{\circ} 55^{\prime} 00^{\prime \prime} \mathrm{D}$ & 1261 \\
\hline Tuzluca İlçesi & $40^{\circ} 02^{\prime} 49.5^{\prime \prime} \mathrm{N} 43^{\circ} 44^{\prime} 41.5^{\prime \prime} \mathrm{E}$ & 1102 \\
\hline
\end{tabular}

Tablo 2. Iğdır ilinin uzun ylllar (1950-2018) ve 2018 yll yetişme sezonuna ait iklim verileri

\begin{tabular}{ccccccc}
\hline \multirow{2}{*}{ Aylar } & \multicolumn{2}{c}{ Yağış $(\mathbf{m m})$} & \multicolumn{2}{c}{ Sicaklık $\left.\mathbf{(}^{\mathbf{(}} \mathbf{C}\right)$} & \multicolumn{2}{c}{ Nispi Nem $(\%)$} \\
\cline { 2 - 7 } & $\begin{array}{c}\text { Yetişme } \\
\text { Sezonu }\end{array}$ & UYO** & $\begin{array}{c}\text { Yetişme } \\
\text { Sezonu }\end{array}$ & UYO & $\begin{array}{c}\text { Yetişme } \\
\text { Sezonu }\end{array}$ & UYO \\
\hline Mart & 16.5 & 21.9 & 12.3 & 6.99 & 45.7 & 52.2 \\
\hline Nisan & 18.2 & 37.4 & 14.2 & 13.4 & 47.7 & 49.9 \\
\hline Mayıs & 69.3 & 49.4 & 18.4 & 17.5 & 45.7 & 51.5 \\
\hline Haziran & 31.8 & 33.1 & 23.4 & 22.3 & 46.1 & 47.3 \\
\hline Temmuz & 5.9 & 14.5 & 29.2 & 26.2 & 45.1 & 45.3 \\
\hline Ăgustos & 5.8 & 9.6 & 26.4 & 25.6 & 52.6 & 47.1 \\
\hline Eylül & 0.3 & 10 & 24.5 & 20.8 & 53.3 & 50.9 \\
\hline Ekim & 33.1 & 28.1 & 12.8 & 13.3 & 71.3 & 62.9 \\
\hline Toplam/Ort & 180.9 & 204.0 & 20.2 & 18.3 & 50.9 & 50.9 \\
\hline
\end{tabular}

*Meteoroloji Genel Müdürlüğü, 2018; **Uzun yıllar ortalamas1

Tablo 3. Deneme alanından alınan toprak örneklerine ait dĕgerler

\begin{tabular}{cc}
\hline İncelenen Toprak Özellikleri & Değerler \\
\hline pH & 8.34 \\
\hline Kireç (\%) & 11.08 \\
\hline EC $(\mathbf{m S} / \mathbf{c m})$ & 1.03 \\
\hline Organik Madde $(\%)$ & 1.18 \\
\hline $\mathbf{P}(\mathbf{p p m})$ & 2.61 \\
\hline $\mathbf{K}(\mathbf{p p m})$ & 1.79 \\
\hline $\mathbf{C a}(\mathbf{p p m})$ & 16.67 \\
\hline $\mathbf{M g}(\mathbf{p p m})$ & 6.4 \\
\hline
\end{tabular}

Deneme alanına ait toprak örnekleri deneme alanını temsil edecek şekilde 0-30 cm derinlikten alınarak toprak analizi yapılmıştır (Tablo 3). Toprak tekstürü Bouyoucos hidrometre yöntemi kullanılarak belirlenmiştir (Bouyoucos, 1955). Toprak reaksiyonu $(\mathrm{pH})$ 1;2.5 toprak:su karışımında cam elektrotlu $\mathrm{pH}$ metre ile belirlenmiştir (Jackson, 1973). Elektriksel iletkenlik $\left(\mathrm{EC} \mathrm{dSm}^{-1)}\right.$ ekstraksiyon süzeklerinde elektriksel kondüktivite aleti ile belirlenmiştir (Rhoades, 1983). Kireç içeriği $\left(\mathrm{CaCO}_{3}\right)$ Scheibler kalsimetresi ile belirlenmiştir (Çağlar, 1949). Organik madde içeriği Smith-Weldon yöntemi kullanılarak belirlenmiştir 
(Nelson and Sommers, 1982). Elverişli Fosfor $\left(\mathrm{P}_{2} \mathrm{O}_{5}\right)$ asit florürde mavi renk yöntemi ile (Sağlam, 1994) değişebilir K, Ca ve $\mathrm{Mg}$ sodyum asetatla (1N, pH:8,2) ekstraksiyonu ile belirlenmiştir (Rhoades, 1983). Elde edilen sonuçlara göre deneme alanına ait toprak killi tınlı bünyede olup, EC 1,03 ile tuzluluk oranı az, $\mathrm{pH}$ 's 18,34 ile orta alkali, organik madde oranı 1,18 ile düşük, kireç \%11,08 ile yüksek olduğu belirlenmiştir (Tablo 3).

Hasat işlemleri \% 10 çiçeklenme ile birlikte toprak yüzeyinde $5 \mathrm{~cm}$ anız kalacak şekilde yapılmıştır. Her popülasyon için alınan bitki örnekleri kurutulduktan $\left(65^{\circ} \mathrm{C}\right)$ sonra ögütme değirmeninde ögütülerek Mikro Kjeldahl metoduna göre toplam azot tayini yapılmışve elde edilen $\% \mathrm{~N}$ azot oranları 6,25 katsayısı ile çarpılarak bitkinin ham protein oranları belirlenmiştir(AOAC, 1997). Daha sonra nötr çözücülerde çözünemeyen lif (NDF), Asit çözücülerde çözünemeyen lif (ADF), Asit çözücülerde çözünemeyen lignin (ADL) Van Soest ve ark. (1991)'e göre belirlenmiştir. Ayrıca Kuru Madde Sindirilebilirliği (KMS), Kuru madde tüketimi (KMT), Sindirilebilir Enerji Miktarı (SE), Metabolik Enerji (ME) ve Nispi yem değeri (NYD) değerleri belirlenmiştir (Fonnesbeck ve ark., 1984; Khalil ve ark., 1986; Sheaffer et al. 1995; Morrison, 2003).

Çalışma sonucunda elde edilen kalite özelliklerinin varyans analizleri ve Duncan çoklu karşılaştırma testleri SPSS 17.0 istatistik paket programında yapılmıştır.

\section{Araştırma Sonuçları ve Tartışma}

Kalite özelliklerine ait varyans analizi incelendiğinde yonca genotiplerine ait HP, NDF, ADF, ADL, KMS, SE, ME, KMT ve NYD değerlerinde genotipler arasındaki fark $\mathrm{p}<0,01$ ihtimal düzeyinde önemli bulunmuştur. Yonca genotiplerinde popülasyonlar arasında $\mathrm{HP}, \mathrm{NDF}, \mathrm{ADF}, \mathrm{ADL}, \mathrm{KMS}, \mathrm{SE}, \mathrm{ME}$, KMT ve NYD değerlerine ait ortalamalarda oluşan farklılıkların belirlenmesi için her bir kriter için Duncan analizi yapılmıştır.

\subsection{Ham protein (HP) oranı (\%)}

Tablo 4 incelendiğinde yonca genotiplerine ait HP oranları \% 15,92-22,31 değerleri arasında değişim göstermektedir. Yonca genotipleri için en düşük HP oranı $\% 15,92$ ile 33 numaral genotip ve en yüksek HP oranı ise $\% 22,31$ ile 4 numaralı yonca genotipi olduğu belirlenmiştir. Ayrıca yonca genotiplerine ait ortalama HP oranı \%19,37 olarak elde edilmiştir. Kayseri (\%18.24) çeşidi ortalama HP değerinin altında çıkarken Sunter (\%21.73) çeşidi ortalama HP değerinin üzerinde bir sonuç elde edilmiştir. Açıkgöz ve ark. (1984), bazı yonca çeşitlerinde HP oranlarının \%15,2-17,1 değerleri arasında değiştiğini ve ortalama HP oranı ise \%16,1 olark bildirmişlerdir. Altınok ve Karakaya (2002), bazı yonca çeşitlerinde HP oranlarını \%21-25 değerleri arasında değiştiğini bildirmiş̧lerdir. Dumlu ve ark. (2017), 2 farklı lokasyonda bazı yonca şeçitlerinde elde ettikleri ortalama HP oranları \%16,78-19,01 değerleri arasında değiştiğini, Açıkbaş ve ark. (2017), doğal yonca genotiplerinde en düşük HP oranı \%17,4 ve en yüksek HP oranı ise \%22,6 ve ortalama HP oranı ise \%19,6 olduğunu bildirmişlerdir. Gökalp ve ark. (2017), Tokat şartlarında bazı yonca çeşitlerinde HP oranlarının \%17,16-18,88, Y1lmaz ve Albayrak (2016), Isparta koşullarında bazı yonca çeşitlerinde HP oranlarının \%16-23-1753 değerleri arasında değiştiğini bildirmişlerdir. Saruhan ve Kuşvuran (2011), bazı yonca genotiplerinde yapmış oldukları verim çalışmasında HP oranlarının \%17,94-22,67 değerleri arasında değiştiğini ve ortalama HP oranının ise \%20,31 olarak bildirmişlerdir. Engin ve Mut (2017), bazı yonca çeşitlerinde kalite ve ot verimi üzerine yaptıkları çalışmada ortalama HP oranının \%22,7 bildirmişlerdir. Kır ve Soya (2008), mera tipi yonca çeşitlerinde verim ve kalite özellikleri açısından değerlendirdikleri bazı yonca çeşitlerinde HP oranlarının $\%$ 17,86-20,26 arasında değiştiğini bildirmişlerdir. Elde edilen HP sonuçları diğer literatür çalışmalarıyla benzer sonuçlar göstermiştir.

\subsection{NDF (Nötr çözücülerde çözünmeyen lif) oranı (\%)}

Tablo 4 incelendiğinde, yonca genotiplerinden elde edilen NDF oranları \%37,42-49,29 değerleri arasında elde edilmiştir. Yonca genotipleri arasında en düşük NDF oranı \%37,42 ile Sunter çeşidinde belirlenmiştir. Yonca genotipleri arasında en yüksek NDF oranı \%49,29 ile 8 numaralı yonca genotipi olmuştur. Yonca genotipleri arasında ayrıca ortalama NDF oranı ise \%43,64 olarak elde edilmiştir. Dumlu ve ark. (2017), 2 farklı lokasyonda bazı yonca şeçitlerinde elde ettikleri ortalama NDF oranlarının \%42,67-44,28 değerleri arasında değiştiğini bildirmişlerdir. Açıkbaş ve ark. (2017), doğal yonca genotiplerinde en düşük NDF oranı $\% 39,5$ ve en yüksek NDF oranı ise $\% 42,6$, ayrica ortalama NDF oranı ise \%41,2 olarak bildirmişlerdir. Yılmaz ve Albayrak (2016), Isparta koşullarında bazı yonca çeşitlerinde NDF oranlarının \%42,27-44,98, Engin ve Mut (2017), bazı yonca çeşitlerinde kalite ve ot verimi üzerine yaptıkları çalışmada ortalama NDF oranının \%43,5 olduğunu bildirmişlerdir. Elde ettiğimiz NDF oranlarının ve ortalama NDF oranı diğer çalışmalarla benzerlik göstermektedir.

\subsection{ADF (Asit çözücülerde çözünmeyen lif) oranı} (\%)

Tablo 4 incelendiğinde, ADF oranları \%26,50-38,69 değerleri arasında değişim göstermektedir. Yonca genotiplerine ait en düşük ADF oranı \%26,50 ile Sunter yonca çeşidinde, en yüksek ADF oranı ise \%38,69 ile 33 numaralı yonca genotipi olmuştur. Yonca bitkilerine ait ortalama ADF oranı ise \%32,63 olarak belirlenmiştir. Dumlu ve ark. (2017), 2 farklı lokasyonda bazı yonca şeçitlerinde elde ettikleri ortalama ADF oranlarının \%38,60-40,32 değerleri arasında değiştiğini, Açıkbaş ve ark. (2017), doğal yonca genotiplerinde en düşük ADF oranının $\% 28,7$ ve en yüksek ADF oranının ise $\% 32,9$ olduğunu ayrıca ortalama ADF oranının ise \%31,6 olduğunu bildirmişlerdir. Yılmaz ve Albayrak (2016), Isparta koşullarında bazı yonca çeşitlerinde ADF oranlarının \%30,26-33,44, Engin ve Mut (2017), bazı yonca çeşitlerinde kalite ve ot verimi üzerine yaptıkları çalışmada ortalama ADF oranının \%30,3 olarak bildirmişlerdir. Elde ettiğimiz ADF oranları Dumlu ve ark. (2017)'nın elde etiiği değerlerden düşük ancak Açıkbaş ve ark. (2017), Y1lmaz ve Albayrak (2016), Engin ve Mut (2017)'nın yaptığı çalışmalarla benzerlik göstermektedir.

\subsection{ADL (Asit çözücülerde çözünemeyen lignin) oranı (\%)}

Tablo 4 incelendiğinde, yonca genotiplerine ait ADL oranları \%4,51-7,18 değerleri arasında değişmektedir. Yonca genotiplerine ait en düşük ADL oranı $\% 4,51$ ile sırasıyla 18 numaralı yonca genotipi olduğu belirlenmiştir. 
Tablo 4. Genotiplere ait HP, NDF, ADF, ADL, KMS, SE, ME, KMT ve NYD değerleri

\begin{tabular}{|c|c|c|c|c|c|c|c|c|c|}
\hline $\begin{array}{c}\text { Gen. } \\
\text { No }\end{array}$ & $\begin{array}{l}\text { HP } \\
(\%)\end{array}$ & $\begin{array}{l}\text { NDF } \\
(\%)\end{array}$ & $\begin{array}{l}\text { ADF } \\
(\%)\end{array}$ & $\begin{array}{l}\text { ADL } \\
(\%)\end{array}$ & $\begin{array}{l}\text { KMS } \\
(\%)\end{array}$ & $\begin{array}{c}\mathbf{S E} \\
\left({\left.\mathbf{M c a l ~} \mathbf{~ k g}^{-1}\right)}\right.\end{array}$ & $\begin{array}{c}\text { ME } \\
\text { (Mcal kg-1) }\end{array}$ & $\begin{array}{c}\text { KMT } \\
(\%)\end{array}$ & NYD \\
\hline 1 & 20.67 a-e & $44.88 \mathrm{a}-\mathrm{d}$ & $30.22 \mathrm{~b}-1$ & $5.48 \mathrm{~b}-\mathrm{g}$ & $67.36 \mathrm{a}-\mathrm{i}$ & $3.15 \mathrm{a}-1$ & $2.59 \mathrm{a}-\mathrm{i}$ & $2.68 \mathrm{c}-\mathrm{f}$ & 140.11 ç-i \\
\hline 2 & $21.92 \mathrm{abc}$ & $44.00 \mathrm{a}-\mathrm{f}$ & $28.41 \mathrm{~d}-1$ & $5.20 \mathrm{ç-g}$ & $69.38 \mathrm{a}-\mathrm{ç}$ & $3.24 \mathrm{a}-\mathrm{ç}$ & $2.66 \mathrm{a}-\mathrm{c}$ & $2.74 \mathrm{c}-\mathrm{f}$ & $147.16 \mathrm{a}-1$ \\
\hline 3 & 19.18 b-i & $45.48 \mathrm{a}-\mathrm{d}$ & $30.85 \mathrm{~b}-1$ & $5.72 \mathrm{a}-\mathrm{g}$ & $66.22 \mathrm{a}-\mathrm{i}$ & $3.10 \mathrm{a}-\mathrm{i}$ & $2.55 \mathrm{a}-\mathrm{i}$ & $2.65 \mathrm{c}-\mathrm{f}$ & 136.95 ç-i \\
\hline 4 & $22.31 \mathrm{a}$ & $47.14 \mathrm{a}-\mathrm{ç}$ & $34.16 \mathrm{a}-\mathrm{f}$ & $6.26 \mathrm{a}-\mathrm{f}$ & $64.80 a-j$ & $3.04 \mathrm{a-j}$ & $2.5 \mathrm{a}-\mathrm{j}$ & 2.55 ç-f & $127.87 \mathrm{f}-\mathrm{i}$ \\
\hline 5 & $16.99 \mathrm{~h}-\mathrm{j}$ & $45.06 \mathrm{a}-\mathrm{d}$ & $34.65 \mathrm{a}-\mathrm{e}$ & $6.42 \mathrm{a}-\mathrm{f}$ & $62.17 \mathrm{f}-\mathrm{j}$ & $2.93 \mathrm{f}-\mathrm{j}$ & $2.4 \mathrm{f}-\mathrm{j}$ & $2.68 c-f$ & $128.75 \mathrm{f}-\mathrm{i}$ \\
\hline 6 & $16.751-\mathrm{j}$ & $47.42 \mathrm{abc}$ & $35.14 \mathrm{a}-\mathrm{d}$ & $6.24 \mathrm{a}-\mathrm{f}$ & $61.66 \mathrm{~g}-\mathrm{j}$ & $2.91 \mathrm{~g}-\mathrm{j}$ & $2.39 \mathrm{~g}-\mathrm{j}$ & 2.54 ç-f & $121.8 \mathrm{~g}-\mathrm{i}$ \\
\hline 7 & 20.61 a-e & $43.19 \mathrm{a}-\mathrm{g}$ & $30.29 \mathrm{~b}-1$ & $5.66 \mathrm{a}-\mathrm{g}$ & $67.28 \mathrm{a}-\mathrm{i}$ & $3.15 \mathrm{a}-\mathrm{i}$ & $2.59 \mathrm{a}-\mathrm{i}$ & $2.79 \mathrm{~b}-\mathrm{f}$ & $145.60 \mathrm{a}-1$ \\
\hline 8 & $16.681-j$ & $49.29 \mathrm{a}$ & $35.17 \mathrm{a}-\mathrm{d}$ & $6.46 \mathrm{a}-\mathrm{e}$ & $61.61 \mathrm{~g}-\mathrm{j}$ & $2.90 \mathrm{~h}-\mathrm{j}$ & $2.39 \mathrm{~g}-\mathrm{j}$ & $2.43 \mathrm{f}$ & $116.30 \mathrm{1i}$ \\
\hline 9 & 20.84 a-e & $41.53 \mathrm{c}-\mathrm{g}$ & $28.11 \mathrm{e}-1$ & $5.12 \mathrm{~d}-\mathrm{g}$ & $69.17 \mathrm{a}-$ & $3.23 \mathrm{a}-\mathrm{d}$ & $2.65 \mathrm{a}-\mathrm{d}$ & $2.93 \mathrm{a}-\mathrm{d}$ & $158.26 \mathrm{a}-\mathrm{f}$ \\
\hline 10 & 18.71 ç-j & $43.68 \mathrm{a}-\mathrm{g}$ & $32.08 \mathrm{a}-1$ & $6.04 \mathrm{a}-\mathrm{f}$ & $65.01 \mathrm{a}-\mathrm{j}$ & $3.05 \mathrm{a-j}$ & $2.51 \mathrm{a}-\mathrm{i}$ & $2.77 \mathrm{~b}-\mathrm{f}$ & 140.22 ç-i \\
\hline 11 & 20.59 a-e & $43.02 \mathrm{a}-\mathrm{g}$ & $29.72 \mathrm{c}-1$ & $5.72 \mathrm{a}-\mathrm{g}$ & 67.74 a- & $3.17 \mathrm{a}-\mathrm{h}$ & $2.6 \mathrm{a}-\mathrm{h}$ & $2.79 \mathrm{~b}-\mathrm{f}$ & $146.81 \mathrm{a}-1$ \\
\hline 12 & $16.43 \mathrm{ij}$ & $47.55 \mathrm{abc}$ & $34.04 \mathrm{a}-\mathrm{g}$ & $6.36 \mathrm{a}-\mathrm{f}$ & 62.43 e-j & $2.94 \mathrm{e}-\mathrm{j}$ & $2.41 \mathrm{e}-\mathrm{j}$ & $2.53 \mathrm{def}$ & $122.48 \mathrm{~g}-\mathrm{i}$ \\
\hline 13 & $18.99 \mathrm{~b}-\mathrm{i}$ & $43.30 \mathrm{a}-\mathrm{g}$ & 34.59 a-e & $6.09 \mathrm{a}-\mathrm{f}$ & $63.06 \mathrm{c}-\mathrm{j}$ & $2.97 \mathrm{c}-\mathrm{j}$ & $2.44 c-j$ & 2.77 b-f & $135.82 \mathrm{~d}-\mathrm{i}$ \\
\hline 14 & 19.48 a-i & $43.40 \mathrm{a}-\mathrm{g}$ & $33.66 \mathrm{a}-\mathrm{h}$ & $6.51 \mathrm{a}-\mathrm{e}$ & $64.02 \mathrm{~b}-\mathrm{j}$ & $3.01 \mathrm{~b}-\mathrm{j}$ & $2.47 \mathrm{~b}-\mathrm{j}$ & $2.76 c-f$ & 137.25 ç-i \\
\hline 15 & $20.29 \mathrm{a}-\mathrm{f}$ & $41.60 \mathrm{c}-\mathrm{g}$ & $28.61 \mathrm{~d}-1$ & $5.41 \mathrm{~b}-\mathrm{g}$ & $68.53 \mathrm{a}-\mathrm{f}$ & $3.20 \mathrm{a}-\mathrm{f}$ & $2.63 \mathrm{a}-\mathrm{f}$ & $2.9 \mathrm{a}-\mathrm{e}$ & $154.36 \mathrm{a}-\mathrm{g}$ \\
\hline 16 & $19.32 \mathrm{a}-\mathrm{i}$ & $43.16 \mathrm{a}-\mathrm{g}$ & $33.80 \mathrm{a}-\mathrm{h}$ & $6.27 \mathrm{a}-\mathrm{f}$ & $63.84 \mathrm{~b}-\mathrm{j}$ & 3.01 b-j & $2.47 \mathrm{~b}-\mathrm{j}$ & $2.79 \mathrm{~b}-\mathrm{f}$ & 137.65 ç-i \\
\hline 17 & $18.88 \mathrm{~b}-\mathrm{j}$ & 40.92 ç-g & $33.63 \mathrm{a}-\mathrm{h}$ & $6.63 \mathrm{a}-\mathrm{d}$ & $63.80 \mathrm{~b}-\mathrm{j}$ & $3.00 \mathrm{~b}-\mathrm{j}$ & $2.46 \mathrm{~b}-\mathrm{j}$ & $2.96 \mathrm{a}-\mathrm{ç}$ & $146.44 \mathrm{a}-1$ \\
\hline 18 & $18.41 \mathrm{~d}-\mathrm{j}$ & $46.55 \mathrm{a}-\mathrm{c}$ & $27.10 \mathrm{~h}-1$ & $4.51 \mathrm{~g}$ & 68.99 a-e & $3.22 \mathrm{a}-\mathrm{e}$ & $2.64 \mathrm{a}-\mathrm{e}$ & 2.59 ç-f & 138.92 ç-i \\
\hline 19 & 19.47 a-i & $42.37 \mathrm{c}-\mathrm{g}$ & $31.86 \mathrm{a}-1$ & $5.80 \mathrm{a}-\mathrm{g}$ & $65.51 \mathrm{a}-\mathrm{i}$ & $3.07 \mathrm{a}-\mathrm{i}$ & $2.52 \mathrm{a}-\mathrm{i}$ & $2.83 \mathrm{a}-\mathrm{f}$ & $143.91 \mathrm{~b}-\mathrm{i}$ \\
\hline 20 & $21.97 \mathrm{ab}$ & $37.83 \mathrm{fg}$ & $27.43 \mathrm{f}-1$ & $5.05 \mathrm{e}-\mathrm{g}$ & $70.21 \mathrm{ab}$ & $3.27 \mathrm{ab}$ & $2.69 \mathrm{ab}$ & $3.18 \mathrm{ab}$ & $173.24 \mathrm{a}-\mathrm{c}$ \\
\hline 21 & $19.24 \mathrm{a}-\mathrm{i}$ & $45.61 \mathrm{a}-\mathrm{d}$ & $34.80 \mathrm{a}-\mathrm{e}$ & $6.41 \mathrm{a}-\mathrm{f}$ & $62.98 \mathrm{c}-\mathrm{j}$ & 2.96 ç-j & $2.44 c-j$ & $2.64 c-f$ & $129.38 \mathrm{f}-\mathrm{i}$ \\
\hline 22 & $17.25 \mathrm{f}-\mathrm{j}$ & $43.93 \mathrm{a}-\mathrm{f}$ & $32.48 \mathrm{a}-1$ & $5.81 \mathrm{a}-\mathrm{g}$ & $64.06 \mathrm{~b}-\mathrm{j}$ & $3.01 \mathrm{~b}-\mathrm{j}$ & $2.47 \mathrm{~b}-\mathrm{j}$ & $2.74 c-f$ & $136.14 \mathrm{~d}-\mathrm{i}$ \\
\hline 23 & 19.83 a-h & 45.48 a-d & $33.49 \mathrm{a}-\mathrm{h}$ & $6.12 \mathrm{a}-\mathrm{f}$ & $64.32 a-j$ & $3.02 \mathrm{a}-\mathrm{j}$ & $2.48 \mathrm{~b}-\mathrm{j}$ & $2.65 c-f$ & $132.58 \mathrm{e}-\mathrm{i}$ \\
\hline 24 & $18.49 \mathrm{~d}-\mathrm{j}$ & $44.25 \mathrm{a}-\mathrm{e}$ & $36.06 \mathrm{a}-c ̧$ & $6.76 \mathrm{abc}$ & $61.63 \mathrm{~g}-\mathrm{j}$ & $2.91 \mathrm{~g}-\mathrm{j}$ & $2.39 \mathrm{~g}-\mathrm{j}$ & $2.72 \mathrm{c}-\mathrm{f}$ & $130.51 \mathrm{f}-\mathrm{i}$ \\
\hline 25 & $20.20 \mathrm{a}-\mathrm{g}$ & $37.84 \mathrm{fg}$ & $27.22 \mathrm{~g}-1$ & $5.07 \mathrm{efg}$ & 69.64abc & $3.25 \mathrm{abc}$ & $2.67 \mathrm{abc}$ & $3.21 \mathrm{a}$ & $173.84 \mathrm{ab}$ \\
\hline 26 & $18.29 \mathrm{~d}-\mathrm{j}$ & $46.75 \mathrm{a}-\mathrm{ç}$ & $36.28 \mathrm{a}-\mathrm{c}$ & $6.69 \mathrm{a}-\mathrm{c}$ & $61.36 \mathrm{~h}-\mathrm{j}$ & $2.90 \mathrm{~h}-\mathrm{j}$ & $2.38 \mathrm{~h}-\mathrm{j}$ & 2.57 ç-f & $122.3 \mathrm{~g}-\mathrm{i}$ \\
\hline 27 & $18.33 \mathrm{~d}-\mathrm{j}$ & $45.71 \mathrm{a}-\mathrm{d}$ & 35.01 a-e & $6.69 \mathrm{a}-\mathrm{ç}$ & $62.43 \mathrm{e}-\mathrm{j}$ & $2.94 \mathrm{e}-\mathrm{j}$ & $2.42 \mathrm{~d}-\mathrm{j}$ & $2.64 \mathrm{c}-\mathrm{f}$ & $127.9 \mathrm{f}-\mathrm{i}$ \\
\hline 28 & $17.85 \mathrm{e}-\mathrm{j}$ & $47.28 \mathrm{abc}$ & $36.63 \mathrm{abc}$ & $6.62 \mathrm{a}-\mathrm{d}$ & 60.89 iij & $2.88 \mathrm{1-j}$ & $2.36 \mathrm{iij}$ & 2.55 ç-f & $120.76 \mathrm{hii}$ \\
\hline 29 & 20.34 a-e & $41.75 \mathrm{c}-\mathrm{g}$ & $30.35 \mathrm{~b}-1$ & $5.58 \mathrm{~b}-\mathrm{g}$ & $67.12 \mathrm{a}-\mathrm{i}$ & $3.14 \mathrm{a}-\mathrm{i}$ & $2.58 \mathrm{a}-\mathrm{i}$ & $2.88 \mathrm{a}-\mathrm{e}$ & 149.94 a-h \\
\hline 30 & $20.63 \mathrm{a}-\mathrm{e}$ & $42.02 \mathrm{c}-\mathrm{g}$ & $33.42 \mathrm{a}-\mathrm{h}$ & $6.36 \mathrm{a}-\mathrm{f}$ & $64.72 a-j$ & $3.04 \mathrm{a-j}$ & $2.5 \mathrm{a}-\mathrm{j}$ & $2.87 \mathrm{a}-\mathrm{e}$ & $144.48 \mathrm{~b}-\mathrm{i}$ \\
\hline 31 & $18.14 \mathrm{e}-\mathrm{j}$ & $45.12 \mathrm{a}-\mathrm{d}$ & $36.14 \mathrm{a}-c ̧$ & $6.87 \mathrm{a}-\mathrm{b}$ & $61.42 \mathrm{~h}-\mathrm{j}$ & $2.90 \mathrm{~h}-\mathrm{j}$ & $2.38 \mathrm{~h}-\mathrm{j}$ & $2.66 c-f$ & $126.66 \mathrm{f}-\mathrm{i}$ \\
\hline 32 & $19.92 \mathrm{a}-\mathrm{h}$ & $43.21 \mathrm{a}-\mathrm{g}$ & $32.43 a-1$ & $6.22 \mathrm{a}-\mathrm{b}$ & $65.23 \mathrm{a}-\mathrm{i}$ & $3.06 \mathrm{a}-\mathrm{i}$ & $2.51 \mathrm{a}-\mathrm{i}$ & $2.79 \mathrm{~b}-\mathrm{f}$ & $141.43 \mathrm{c}-\mathrm{i}$ \\
\hline 33 & $15.92 \mathrm{j}$ & $48.74 \mathrm{ab}$ & $38.69 \mathrm{a}$ & $7.18 \mathrm{a}$ & $58.39 \mathrm{j}$ & $2.77 \mathrm{j}$ & $2.27 \mathrm{j}$ & $2.47 \mathrm{ef}$ & $112.12 \mathrm{i}$ \\
\hline 34 & $19.85 a-h$ & $45.54 \mathrm{a}-\mathrm{d}$ & $36.74 \mathrm{ab}$ & $6.73 \mathrm{a}-\mathrm{c}$ & $61.64 \mathrm{~g}-\mathrm{j}$ & $2.91 \mathrm{~g}-\mathrm{j}$ & $2.39 \mathrm{~g}-\mathrm{j}$ & $2.64 c-f$ & $126.15 \mathrm{f}-\mathrm{i}$ \\
\hline 35 & 20.70 a-e & $44.54 \mathrm{a}-\mathrm{d}$ & 34.27 a-f & $6.40 \mathrm{a}-\mathrm{f}$ & $64.04 \mathrm{~b}-\mathrm{j}$ & $3.01 \mathrm{~b}-\mathrm{j}$ & $2.47 \mathrm{~b}-\mathrm{j}$ & $2.7 \mathrm{c}-\mathrm{f}$ & $133.9 \mathrm{~d}-\mathrm{i}$ \\
\hline 36 & 19.12 b-i & $42.69 \mathrm{~b}-\mathrm{g}$ & $34.69 \mathrm{a}-\mathrm{e}$ & $6.32 \mathrm{a}-\mathrm{f}$ & $63.03 \mathrm{c}-\mathrm{j}$ & $2.97 \mathrm{c-j}$ & 2.43 ç-j & $2.82 \mathrm{a}-\mathrm{f}$ & 137.74 ç-i \\
\hline 37 & 19.35 a-i & $41.30 \mathrm{c}-\mathrm{g}$ & $33.64 \mathrm{a}-\mathrm{h}$ & 6.15 a-f & 63.99 b-j & $3.01 \mathrm{~b}-\mathrm{j}$ & $2.47 \mathrm{~b}-\mathrm{j}$ & $2.91 \mathrm{a}-\mathrm{d}$ & $144.68 \mathrm{a}-\mathrm{i}$ \\
\hline 38 & 20.76 a-e & $43.17 \mathrm{a}-\mathrm{g}$ & $35.03 \mathrm{a}-\mathrm{e}$ & $6.57 \mathrm{a}-\mathrm{e}$ & $63.44 \mathrm{c}-\mathrm{j}$ & $2.99 \mathrm{c-j}$ & $2.45 c-j$ & 2.79 b-f & 137.16 ç-i \\
\hline 39 & 20.70 a-e & $37.56 \mathrm{~g}$ & $31.26 \mathrm{~b}-1$ & $5.88 \mathrm{a}-\mathrm{g}$ & $66.52 a-i$ & $3.12 \mathrm{a}-\mathrm{i}$ & $2.56 \mathrm{a}-\mathrm{i}$ & $3.21 \mathrm{a}$ & $165.37 \mathrm{a}-\mathrm{d}$ \\
\hline 40 & $18.87 \mathrm{c}-\mathrm{j}$ & $45.13 \mathrm{a}-\mathrm{d}$ & 34.78 a-e & $6.58 \mathrm{a}-\mathrm{e}$ & 62.85 ç-j & $2.96 \mathrm{c}-\mathrm{j}$ & $2.43 c ̧-j$ & $2.67 \mathrm{c}-\mathrm{f}$ & $130.06 \mathrm{f}-\mathrm{i}$ \\
\hline 41 & $17.20 \mathrm{~g}-\mathrm{j}$ & $45.13 \mathrm{a}-\mathrm{d}$ & $34.29 \mathrm{a}-\mathrm{f}$ & $6.39 \mathrm{a}-\mathrm{f}$ & $62.55 \mathrm{~d}-\mathrm{j}$ & $2.95 \mathrm{~d}-\mathrm{j}$ & $2.42 \mathrm{~d}-\mathrm{j}$ & $2.67 \mathrm{c}-\mathrm{f}$ & $129.47 \mathrm{f}-1$ \\
\hline 42 & $21.31 \mathrm{a}-\mathrm{d}$ & $41.58 \mathrm{c}-\mathrm{g}$ & $30.34 \mathrm{~b}-1$ & $5.63 \mathrm{~b}-\mathrm{g}$ & $67.54 a-1$ & $3.16 \mathrm{a}-1$ & $2.59 \mathrm{a}-1$ & 2.9 ae & 151.64 a-h \\
\hline 43 & $18.90 \mathrm{~b}-\mathrm{j}$ & $43.00 \mathrm{a}-\mathrm{g}$ & $31.08 \mathrm{~b}-1$ & $6.22 \mathrm{a}-\mathrm{f}$ & $65.91 \mathrm{a}-\mathrm{i}$ & $3.09 \mathrm{a}-\mathrm{i}$ & $2.54 \mathrm{a}-\mathrm{i}$ & $2.79 \mathrm{~b}-\mathrm{f}$ & $142.91 \mathrm{~b}-\mathrm{i}$ \\
\hline 44 & $20.05 a-h$ & $43.41 \mathrm{a}-\mathrm{g}$ & $30.15 \mathrm{~b}-1$ & $5.71 \mathrm{a}-\mathrm{g}$ & $67.16 \mathrm{a}-\mathrm{i}$ & $3.15 \mathrm{a}-\mathrm{i}$ & $2.58 \mathrm{a}-\mathrm{i}$ & $2.77 \mathrm{c}-\mathrm{f}$ & $143.97 \mathrm{~b}-\mathrm{i}$ \\
\hline 45 & 20.62 a-e & $39.43 \mathrm{~d}-\mathrm{g}$ & $27.59 \mathrm{f}-1$ & $5.24 \mathrm{c}-\mathrm{g}$ & $69.51 \mathrm{a}-\mathrm{c}$ & $3.24 \mathrm{a}-c ̧$ & $2.66 \mathrm{a}-\mathrm{ç}$ & $3.05 \mathrm{a}-\mathrm{c}$ & 164.39 a-e \\
\hline 46 & 19.68 a-1 & $44.85 \mathrm{a}-\mathrm{d}$ & $33.70 \mathrm{a}-\mathrm{h}$ & $6.28 \mathrm{a}-\mathrm{f}$ & $64.08 \mathrm{~b}-\mathrm{j}$ & 3.02 b-j & $2.47 \mathrm{~b}-\mathrm{j}$ & $2.68 c-f$ & $133.41 \mathrm{~d}-\mathrm{i}$ \\
\hline 47 & 18.82 ç-j & $43.07 \mathrm{a}-\mathrm{g}$ & 29.38 ç-1 & $5.64 \mathrm{a}-\mathrm{g}$ & $67.28 \mathrm{a}-\mathrm{i}$ & $3.15 \mathrm{a}-\mathrm{i}$ & $2.59 \mathrm{a}-\mathrm{i}$ & $2.79 \mathrm{~b}-\mathrm{f}$ & $146.06 \mathrm{a}-1$ \\
\hline 48 & $19.64 a-1$ & $38.22 \mathrm{e}-\mathrm{g}$ & $28.60 \mathrm{~d}-1$ & $5.41 \mathrm{~b}-\mathrm{g}$ & $68.27 \mathrm{a}-$ & $3.19 \mathrm{a}-\mathrm{g}$ & $2.62 \mathrm{a}-\mathrm{g}$ & $3.18 \mathrm{ab}$ & $169.29 \mathrm{a}-\mathrm{c}$ \\
\hline Sunter & $21.73 \mathrm{a}-\mathrm{ç}$ & $37.42 \mathrm{~g}$ & 26.501 & $4.89 \mathrm{fg}$ & $70.87 \mathrm{a}$ & $3.30 \mathrm{a}$ & $2.71 \mathrm{a}$ & $3.21 \mathrm{a}$ & $176.25 \mathrm{a}$ \\
\hline Kayseri & $18.24 \mathrm{~d}-\mathrm{j}$ & $47.12 \mathrm{a}-\mathrm{c}$ & $37.03 \mathrm{ab}$ & $6.93 \mathrm{ab}$ & $60.73 \mathrm{ij}$ & $2.87 \mathrm{ij}$ & $2.36 \mathrm{ij}$ & 2.55 ç-f & 119.88 hii \\
\hline Ort. & 19.37 & 43.64 & 32.63 & 6.05 & 64.93 & 3.06 & 2.50 & 2.77 & 140.01 \\
\hline
\end{tabular}


Yonca genotipleri içinde en yüksek ADL oranı \%7,18 ile 33 numaralı yonca genotipi ve tüm yonca genotiplerine ait ortalama ADL oranı ise \%6,05 olarak elde edilmiştir. Ünalp (2015), farklı gelişme dönemlerinde elde edilen yonca genotiplerinde çiçeklenme dönemine ait ADL oranlarının \%8,49-10,74 değerleri arasında değişim gösterdiğini bildirmişlerdir. Elde etiiğimiz ADL oranları \%10 çiçeklenme dönemine ait olduğu ancak Ünalp (2015)'nın elde ettikleri ADL değerlerinin tam çiçeklenme döneminde elde edildiği için farklılık gösterdiği düşünülmektedir.

\subsection{KMS (Kuru madde sindirilebilirliği) (\%)}

Yonca genotiplerinde KMS değerleri Tablo 4 incelendiğinde \%58,39-70,87 değerleri arasında değişim göstermektedir. Genotiplere ait en düşük KMS oranı \%58,39 ile 33 numarlı yonca genotipi, En yüksek KMS oranları ise \%70,87 ile Sunter yonca çeşidinde olmuştur. Yonca genotiplerine ait ortalama KMS oranı \%64,93 olarak belirlenmiştir. Aksoy ve Yılmaz (2003), yonca genotiplerinde ele ettikleri KMS değerleri \%45,65-58,84 değerleri arasında değiştiğini bildirmişlerdir. Denek ve Deniz (2004), yonca genotiplerinde elde etiikleri KMS değeri \%56,32, Deniz ve ark. (2000), yonca genotiplerinde KMS değerini \%58,56 olarak bildirmişlerdir. Elde edilen KMS oranları diğer literatür çalışmalarında elde edilen KMS oranlarına yakın değerler elde dilmiştir.

\subsection{SE (Sindirilebilir enerji) (Mcal kg-1)}

Tablo 4 incelendiğinde, SE (Sindirilebilir enerji) değerleri arasında en yüksek SE değeri 3,30 Mcal kg-1 ile Sunter yonca çeşidinde ve en düşük SE değeri ise $2,77 \mathrm{Mcal} \mathrm{kg}^{-1}$ ile 33 numaralı yonca genotipi olduğu belirlenmiştir. Tüm yonca genotiplerine ait ortalama SE değeri ise $3,06 \mathrm{Mcal} \mathrm{kg}^{-1}$ olarak elde edilmiştir.

\subsection{ME (Metabolik enerji) (Mcal kg-1)}

Tablo 4'de görüldüğü gibi yonca genotipleri arasında $\mathrm{ME}$ (Metabolik enerji) 2,27-2,71 Mcal $\mathrm{kg}^{-1}$ değerleri arasında dğişmektedir. Yonca genotiplerinde en düşük ME değeri 2,27 mcal kg-1 ile 33 numaralı yonca genotipi, en yüksek ME değeri ise 2,71 mcal kg-1 ile Sunter yonca çeşidinde olduğu belirlenmiştir. Aksoy ve Yılmaz (2003), yonca genotiplerinde elde ettikleri ME değerleri en düşük $1,37 \mathrm{Mcal} \mathrm{kg}^{-1}$ ve en yüksek $1,95 \mathrm{Mcal} \mathrm{kg}^{-1}$ olacak şekilde elde etmişlerdir. Elde etiiğimiz ME değerleri Aksoy ve Y1lmaz (2003), tarafindan bildirilen değerlerden yüksek bulunmuştur.

\subsection{KMT (Kuru madde tüketimi) oranı (\%)}

Tablo 4 incelendiğinde, KMT (Kuru madde tüketimi) oranları \%2,43-3,21 değerleri arasında değişim göstermektedir. Yonca genotiplerine ait en düşük KMT oranı $\% 2,43$ ile 8 numaralı yonca genotipi olmuştur. Yonca genotiplerine ait en yüksek KMT oranı ise \%3,21 ile Sunter yonca çeşidinde olduğu belirlenmiştir. Yonca genotiplerinin tümüne ait ortalama KMT oranı ise \%2,77 olarak elde edilmiştir. Çaçan ve ark. (2012), bazı tek yıllık yonca türlerinde KMT oranlarını \%2,4 ile \%3,1 değerleri arasında değiştiğini belirtmişlerdir.

\subsection{NYD (Nispi yem değeri)}

Tablo 4 incelendiğinde, Yonca genotiplerinde NYD (nisbi yem değeri) 112,12-176,25 değerleri arasında değişim göstermektedir. Yonca genotipleri içerisinde en düşük NYD değeri 112,12 ile 33 numaralı yonca genotipinden elde edilmiştir. Yonca genotiplerinde en yüksek NYD değeri ise 176,25 ile Sunter yonca çeşidinde elde edilmiştir. Yonca genotiplerine ait ortalama NYD değeri ise 140,01 olduğu belirlenmiştir. Açıkbaş ve ark. (2017), doğal yonca genotiplerinde NYD değerlerinin 138,1-154,4 arasında değiştiğini ve ortalama NYD değerinin ise 145,4 olduğunu bildirmişlerdir. Çaçan ve ark. (2012), bazı tek yıllık yonca türlerinde NYD oranlarının 111,4-156,3 arasında değişim gösterdiğini belirtmişlerdir. Çalışmamızda elde edilen NYD değerleri Çaçan ve ark. (2012), Açıkbaş ve ark. (2017)'nın çalışmalarında elde edilen NYD değerleri ile benzerlik göstermektedir.

\section{Sonuç}

$\mathrm{Bu}$ çalışması kapsamında Iğdır ilinin farklı noktalarından toplanarak çoğaltılan yerel genotipler ile günümüz şartlarında ekimi devam eden tescilli çeşitler ile karşılaştırma yapılmıştır. Araştırmada elde edilen sonuçlara göre; yem kalite analizlerinde en yüksek HP oranı 4 numaralı yonca genotipi, istenen en düşük NDF oranı 39 numaralı genotipte elde edilmiştir. Kalite özelliklerinden istenen en düşük ADF oranları Sunter çeşidine en yakın 18, 25 ve 45 numaralı yonca genotiplerinden, en düşük ADL oranı ise 18 numaralı yonca genotipinden elde edilmiştir. KMS ve SE oranlarında sirasiyla 20, 25 ve 45 numaralı yonca genotiplerinden kalite özellikleri açısından Sunter çeşidine en yakın sonuçlar elde edilmiştir. İncelenen parametreler doğrultusunda kalite özellikleri açısından ise 4, 18, 20, 25, 39 ve 45 numaralı yonca genotiplerinde iyileştirmeye yönelik ıslah çalışmaları yapılabilir. Sonuç olarak toplanan yerel genotipler bitki ıslahı ve genetik kaynak muhafazası açısından oldukça önemlidir. Elde edilen bu kaynakların muhafazası ve sonraki ıslah çalışmaları açısından değerlendirilmesi önem arz etmektedir. Elde edilen sonuçlar zirai anlamda değerli bulgular olduğu ve ıslah çalışmalarına 1 şı tutacağı düşünülmektedir. Ayrıca elde edilen kalite özellikleri göz ününde bulundurularak gelecek 1slah çalışmaları projeleri için ebeveyn seçimlerinde önemli sonuçlar elde edilmiştir. Mevcut yonca genotiplerinin yerel genotipler olması ve bunların ıslah çalışmalarıyla yeni çeşitlerin geliştirilmesine olanak sağlayacağı düşünülmektedir.

\section{Teşekkür}

Bu çalışmanın (2016-FBE-D01 Nolu Proje) tüm finansman desteğini sağlayan Iğdır Üniversitesi Bilimsel Araştırma Projeleri Koordinasyon Birimi’ne katkılarından dolayı teşekkür ederiz.

Not: $\mathrm{Bu}$ çalışmaBarış EREN'in Doktora Tez çalışmasından üretilmiştir.

\section{Kaynakça}

Açıkbaş, S., Albayrak, S., \& Mevlüt, T. (2017). Doğal vejetasyondan toplanan bazı yonca (Medicago Sativa L.) genotiplerinin ot verim ve kalitelerinin belirlenmesi. Türkiye Tarımsal Araştırmalar Dergisi, 4(2), 155-162. https://doi.org/10.19159/tutad.293446

Açıkgöz, E., Ekiz, H., \& Karagöz, A. (1984). Ankara kıraç koşullarında bazı yonca çeşitlerinin verim ve önemli tarımsal özellikleri. Uludă̆ Üniv. Zir. Fak. Derg, 3, 33-39. 
Açıkgöz, E. (2001). Yem Bitkileri (3. Baskı). Uludağ üniversitesi güçlendirme vakfı, yayın, (182). ISO 690

Aksoy, A., \& Yilmaz, A. (2003). Bazı Yonca Varyetelerinde Kuru Madde ve Organik Madde Sindirilebilirlikleri ve Metabolik Enerji Değerleri.

Altınok, S., \& Karakaya, A. (2002). Forage yield of different alfalfa cultivars under Ankara conditions. Turkish Journal of Agriculture and Forestry, 26(1), 11-16. ISO 690

AOAC. (1997). Official methods of analysis. association of official analytical chemists. 16. ed. 3. revision. Arlington, VA, USA.

Bouyoucos, J. V., (1955). Self-excited hydrodynamic oscillators. Acoust. Research Laboratory Harvard University Technology Memorial. No. 36.

Çaçan, E., Başbağ, M., \& Aydın, A. (2012). Diyarbakır ili doğal meralarından toplanan bazı tek yıllık yonca türlerinde (Medicago spp.) kalite özelliklerinin belirlenmesi.

Çağlar, K. Ö. (1949). Toprak Bilgisi Ders Kitabı, Ankara Üniv. Ziraat Fak. Yay, (10).

Demirel, F., Eren, B., Demirel, S., \& Erol, A. (2020). Flow Sitometri ve Bitki Islahı. Bursa Uludă̆ Üniversitesi Ziraat Fakültesi Dergisi, 34(1), 213-223.

Denek, N., \& Deniz, S. (2004). The determination of digestibility and metabolizable energy levels of some forages commonly used in ruminant nutrition by in vitro methods. Turkish Journal of Veterinary and Animal Sciences, 28(1), 115-122.

Deniz, S., Denek, N., Karsli, M. A., Yumak, H., \& Nursoy, H. (2000). Farklı batözlerle öğütmenin kaba yemlerin besin madde içeriği ile yem tüketimi ve sindirilme derecesine etkisi. Yüzüncü Yll Üniversitesi Veteriner Fakültesi Dergisi, 11(2), 82-86.

Dumlu, S. E., Çakal, Ş., Aksakal, E., Uzun, M., Özgöz, M. M., Terzioğlu, K., \& Menteşe, Ö. (2017). Erzurum ekolojik koşullarında yonca (Medicago sativa L.) çeşit adayının performansinın belirlenmesi. Alınteri Journal of Agricultural Sciences, 32(2), 55-61. https://doi.org/10.28955/alinterizbd.336014

Elçi, Ş., \& Sevimay, C. S. (1990). Elçi ve Kayseri Yoncalarının Islahında Seçme Bitkilerin Klonla Hızlı Bir şekilde Üretimi için Elverişli Bir Yöntemin Belirlenmesi. Türkiye Bilimsel ve Teknik Araştırma Kurumu Tarım ve Ormancılık Araştırma Grubu, Proje No: TOVAG-610, Ankara.

Engin, B., \& Mut, H. (2017). Farklı yonca çeşitlerinin ot verimi ve bazı kalite özelliklerinin belirlenmesi. Yüzüncü Yll Üniversitesi Tartm Bilimleri Dergisi, 27(2), 212-219. https://doi.org/10.29133/yyutbd.289466

Eren, B. 2014. Yoncaya (Medicago sativa L.) Ait Yabani Aksesyonların, Yerel Çeşitlerin ve Modern Çeşitlerin Morfolojik Özellikler Yönüyle Karşılaştırılmaları, Yüksek Lisans Tezi, Kars, Kafkas Üniversitesi Fen Bilimleri Enstitüsü, s.7-8

Eren, B., Demirel, F., Demirel, S., \& Keskin, B. (2018). Medicago truncatula as Model Plant of Legumes. 1.
Internatıonal Gap Agrıculture \& Livestock Congress 25-27 April, Şanlıurfa/Turkey.

Eren, B., Demirel, F., Kumlay, A. M., \& Yıldırım, B. (2017). Situation of Field Crops in Iğdır Province According to Years. 2nd International Iğdır Symposium, 9-11 October, Iğdır, Turkey.

Ferber, D. (1999). Risks and benefits: GM crops in the cross hairs. Science, 286(5445), 1662-1666.

Fonnesbeck, P. V., Clark, D. H., Garret, W. N., \& Speth, C. F. (1984). Predicting energy utilization from alfalfa hay from the Western Region. Proc. Am. Anim. Sci.(Western Section), 35, 305-308.

Gökalp, S., Yazıcı, L., Cankaya, N., \& İspirli, K. (2017). Bazı yonca (Medicago sativa L.) çeşitlerinin tokat-kazova ekolojik koşullarında ot verimi ve kalite performanslarının belirlenmesi. Gaziosmanpaşa Üniversitesi Ziraat Fakültesi Dergisi, 34(3), 114-127.

Graham, P. H., \& Vance, C. P. (2003). Legumes: importance and constraints to greater use. Plant physiology, 131(3), 872-877.

Jackson, M. L., 1973. Soil chemical Analysis. Prentice-Hall of India Private Limited, New Delhi, India pp. 106-190.

Kaçar, O., Göksu, E., \& Azkan, N. (2005). Bursa koşullarında farklı bakteri suşları ile aşılamanın bazı nohut (cicer arietinum 1.) çeşit ve hatlarında verim ve verim öğeleri üzerine etkisinin belirlenmesi. Ege Üniversitesi Ziraat Fakültesi Dergisi, 42(3), 21-32.

Keskin, B., Temel, S., \& Eren, B. Iğdır Ekolojik Şartlarında Bazı Yonca (Medicago sativa L.) Çeşitlerinin Ot verimleri. Türk Tarım ve Doğa Bilimleri Dergisi, 7(3), 757-764. https://doi.org/10.30910/turkjans.670819

Kır, B., \& Soya, H. (2008). Kimi mera tipi yonca çeşitlerinin bazı verim ve kalite özellikleri üzerinde bir araştırma. Ege Üniversitesi Ziraat Fakültesi Dergisi, 45(1), 11-19.

Khalil, J.K., Sawaya, W.N., Hyder, S.Z., (1986). Nutrient Composition of Atriplex Leaves Grown in Saudi Arabia. J. Range Manage. 39, 104-107.

MGM, (2018). Başbakanlık DMİ Genel Müdürlüğü Meteroloji Bültenleri. Ankara.

Morrison, J.A. (2003). Hay and pasture management. chapter 6. 1llinois agronomy handbook. http://extension.cropsciences.illinois.edu/handbook/pdfs/ch apter06.pdf. Access date: May 5, 2020.

Nelson, D.W., \& Sommers, L.E., (1982). Organic Matter. Methods of Soil Analysis Part2. Chemical and Microbiological Properties Second Edition. Agronamy. pp, 574-579.

Phillips, L. (2006). Food and globalization. Annu. Rev. Anthropol., 35, 37-57.

Rhoades, J.D. (1983). Cation exchange capacity. Methods of Soil Analysis: Part 2 Chemical and Microbiological Properties, 9, 149-157.

Sağlam, M.T. (1994). Toprak ve suyun kimyasal analiz yöntemleri. Trakya Üni. Tekirdağ Ziraat Fak. Yayın, (189). 
Saruhan, V., \& Kuşvuran, A. (2011). Güneydoğu Anadolu Bölgesi koşullarında bazı yonca (Medicago sativa L.) çeşitleri ve genotiplerinin verim performanslarının belirlenmesi. Ege Üniversitesi Ziraat Fakültesi Dergisi, 48(2), 133-140.

Sheaffer, C.C., Peterson, M.A., Mccalin, M., Volene, J.J., Cherney, J.H., Johnson, K.D., \& Viands, D.R. (1995). Acide detergent fiber, neutral detergent fiber concentration and relative feed value. In North American Alfalfa Improvement Conference, Minneapolis.

Suzan, T.M.A., (2008). Farkl Lokasyonlarda Bazl Yonca Çeşitlerinin Yem Verimleri Ve Bitkisel Özellikleri. Yüksek Lisans Tezi, Ankara Üniversitesi Fen Bilimleri Enstitüsü, Ankara. 1.

Sehirali, S., \& Ozgen, M. (1987). Plant genetic resources. Ankara University Agricultural Faculty Publishing, 1020, 212-213.

Şakiroğlu, M., İlhan, D., Kaya, M. M., Demirözoğul, O., Uluçay, O., \& Eren, B. (2011). Moleküler Veriler Işığında Medicago sativa L. Tür Kompleksinin Mevcut Durumu. Kafkas Üniversitesi Fen Bilimleri Enstitüsü Dergisi, 4(1), $32-42$.
Şakiroğlu, M., Eren, B., İlhan, D., \& Tufan, T. (2015). Historical alfalfa landraces perform higher yield under dry farming in Turkey. Procedia Environmental Sciences, 29, 189. DOİ:10.1016/j.proenv.2015.07.254

Ünalp, E. (2015). Farklı gelişme dönemleri ve biçim sıralarında yonca (medicago sativa 1.) kuru otunun ham protein, selüloz ve bazı mikrobiyolojik özelliklerinin belirlenmesi (Master's thesis, Namık Kemal Üniversitesi).

Van Soest, P.V., Robertson, J.B., \& Lewis, B.A. (1991). Methods for dietary fiber, neutral detergent fiber, and nonstarch polysaccharides in relation to animal nutrition. Journal of dairy science, 74(10), 3583-3597.

Verdier, J., Kakar, K., Gallardo, K., Le Signor, C., Aubert, G., Schlereth, A., \& Thompson, R.D. (2008). Gene expression profiling of $\mathrm{M}$. truncatula transcription factors identifies putative regulators of grain legume seed filling. Plant molecular biology, 67(6), 567.

Yılmaz, M., \& Albayrak, S. (2016). Isparta ekolojik koşullarında bazı yonca (Medicago sativa L.) çeşitlerinin ot verim ve kalitelerinin belirlenmesi. Tarla Bitkileri Merkez Araştırma Enstitüsü Dergisi, 42-47. https://doi.org/10.21566/tbmaed.91487 